Research Article

\title{
Construction of Network Multimedia Teaching Platform System of College Sports
}

\author{
Wumei Li and Xiaorui Fan \\ Department of Physical Education, Shandong Management University, Jinan 250300, Shandong, China \\ Correspondence should be addressed to Xiaorui Fan; 14438120191461@sdmu.edu.cn
}

Received 19 May 2021; Revised 13 June 2021; Accepted 1 July 2021; Published 14 July 2021

Academic Editor: Sang-Bing Tsai

Copyright ( 2021 Wumei Li and Xiaorui Fan. This is an open access article distributed under the Creative Commons Attribution License, which permits unrestricted use, distribution, and reproduction in any medium, provided the original work is properly cited.

\begin{abstract}
With the development of computer technology and related disciplines, the application of multimedia technology to education is rapidly becoming the mainstream technology of educational technology. This article mainly researches the construction of college sports network multimedia teaching platform system. The physical education management module is the main module in this sports network teaching platform. Therefore, the physical education management module is tested in the testing process. Each module adopts a black box test method. In the system analysis, by dicing, slicing, rotating, and other operations on the data warehouse constructed with the student's performance data, the data are observed from different angles, which is convenient for the teacher to understand the teaching effect. This article adopts the method of grade evaluation to finally determine a number of indicators that are not contradictory and nonrepetitive. The end of a teaching unit or a series of teaching activities must be evaluated at different levels. The biggest difference between process evaluation and summative evaluation is that it not only attaches importance to objective measurement and quantitative analysis but also attaches importance to the subjective judgment and qualitative analysis of both teaching parties, which requires a combination of the two. The test environment of the system is to simulate the real operating environment of the system. A cloud computing service platform is built in the school's central computer room to provide services such as dynamic resource scheduling and dynamic load balancing. There are very few schools that use college sports networks to develop educational functions, only reaching $7.8 \%$ of the total number of campus networks. The results show that the multimedia teaching platform greatly promotes the teaching effect of college physical education.
\end{abstract}

\section{Introduction}

With the rapid development of modern production and science and technology, the total amount of knowledge has increased sharply, and the speed of knowledge update has accelerated unprecedentedly, which puts forward new and higher requirements for our teaching. The emergence of online teaching has greatly eased the pressure caused by the shortage of facilities and teachers. The implementation of teaching on the network cannot be restricted by time, space, and other conditions and use the characteristics of the network to solve the problems that arise. From the perspective of mobilizing students' learning enthusiasm, physical education network teaching can also make students change from passive knowledge receivers to active ones.
Multimedia teaching is to transfer relevant scientific information to students through this rich and diverse carrier, hoping to improve students' mastery and understanding of relevant scientific knowledge through teaching methods. Some colleges and universities and the majority of sport fans who have not been able to gain professional sport knowledge for some reasons can also gain sport knowledge anytime and anywhere through the online teaching platform; by this way, the sharing of teaching resources is maximized. With the timeliness, interactivity, and display of multimedia network, sports learning can be brought to families, communities, and even any place with network, so as to provide online learning guidance and help for more college students and nonschool sports lovers. 
With the continuous development of network multimedia technology and the continuous improvement of teaching conditions in universities, computers as a modern tool have become popular in the teaching field. The purpose of Armenteros is to enhance people's understanding of the different behavioral intentions of referees and assistant referees in different FIFA leagues and use multimedia teaching materials as learning tools. In order to evaluate the relationship between the structures, he developed an analysis based on structural equation modeling (SEM), especially partial least squares (PLS). Although his research model has high accuracy, there are certain loopholes [1]. In order to improve the multimedia control performance of teaching, Zheng proposed a multimedia engineering teaching system design model based on Internet of things technology. Based on the embedded ARM core, he constructed the overall structure model of the real estate engineering multimedia teaching system design. He realized the integrated control of the system through the decentralized control method and completed the overall design framework of the real estate engineering teaching system. Although his research has extremely high human-computer interaction, the experimental accuracy is not high [2]. Abdurasulovich makes a theoretical analysis of the development of Education under modern conditions, the direction of management methods, and the application of information technology in high schools and universities. He proposed research based on modern forms, methods, and tools (including multimedia technology). The basic method of overall development is based on multimedia technology. The analysis of the experience of world education development shows three main traditions of development: the development of curriculum theory, the concept of permanent education, and the idea of ability clef. His research content is more detailed, but there is a lack of specific algorithm [3]. Liu thinks that with the development of multimedia technology, multimedia-based teaching has become a popular way of education. He mainly studies rule extraction algorithm based on incomplete multiexpert fuzzy linguistic formal decision context. He discussed the corresponding confidence in the concept of fuzzy linguistic decision-making and the support of linguistic decision-making rules. Based on the formal context of fuzzy language, he constructed the concept lattice of multiexpert fuzzy language to deal with the evaluation information of multiexpert language. In order to solve the problem that the weight of experts is unknown, he proposed a method to maximize the deviation in the context of multiexpert fuzzy linguistic form through the distance of linguistic evaluation matrix. In addition, he developed a language aggregation operator for multiexpert fuzzy linguistic concept lattice to obtain association rules. But his research method is more practical, but there is a lack of necessary data [4].

This paper analyzes the network course construction mechanism of China's sports network course and the audience of the network course of China's sports network course, so as to intuitively find the relevant feedback of college students on the application of sports network course, so as to provide reasonable suggestions for the network course construction of China's sports network course, so as to further improve the physical education teaching system of colleges and universities in China. Using the existing computer technology, university network communication technology, data storage, and other technologies, choosing mature, reliable, and practical system platform, development platform and management platform can ensure the smooth and free sharing of regional university sports network education resources in the region and support the normal operation of the system. The innovation of this article is to use the existing computer technology and data storage technology to construct and improve the teaching platform system.

\section{Multimedia Teaching Platform System}

2.1. College Sports Network. The essence of the online teaching platform is a special-purpose teaching and collaborative learning system based on Internet resources, which provides audiences with a large number of speciallearning Internet resources and tools for collaborative learning and communication through the Internet and lets the audience independently choose topics and projects of interest to research. The higher the professional level of the construction of the sports network teaching platform, the higher the requirements for the website builders and maintainers. The professional training of the system must be accepted in order to better construct and play the value of the website $[5,6]$.

The construction and maintenance of any website requires a staff with professional skills, so colleges and universities must cultivate sports information management talents, maintain the management, update of sports websites, and make better use of the rich resources of the school to achieve resource sharing. In the process of teachers' implementation of teaching, teaching design plays a very important role. It is necessary to strengthen the planning of teachers' teaching and the planning of students' learning so that the teaching design is scientific, and it can effectively promote the success of learning [7].

This teaching design is based on the student's dominant position and is dedicated to improving the enthusiasm and initiative of the students. At the same time, the teacher plays a supporting role. Among them, teachers' teaching activities and students' learning activities are parallel. Theory teaching and technical teaching are inseparable in college physical education. Theory teaching is the foundation of college physical education, and technical teaching is the practice of college physical education. Therefore, in college physical education, the unity of theory and practice is very important. Physical education in colleges and universities also need to pay attention to the timely communication and interaction between teaching and learning in the teaching process [8].

Physical education in colleges and universities also pays attention to the implementation of individualized teaching based on personal preference and development. Each ordinary node in the group needs to maintain a state table. The address information of the super nodes in the group is saved. The node only chooses to establish a connection with one of 
the super nodes. When the connected super node suddenly fails and the connection is interrupted, the ordinary node will choose another super node as its own super node $[9,10]$.

2.2. Multimedia Teaching Platform. In the rapid development of the information age, new multimedia technology has spread digital data through the Internet platform. Its biggest feature is that it can transmit multimedia information pages processed by professional editing and production system to each multimedia electronic terminal [11]. Since then, multimedia technology can start to say goodbye to the one-sided and imparting characteristics and change into the technology mode of interaction on multimedia devices. This new technology will make the dissemination of information more convenient and rapid and turn the information transformation and interaction into the instantaneous mode. Multimedia teaching is the combination of text, graphics, animation, video, audio, and other multimedia elements, so as to stimulate learners' multiple senses in teaching and enhance their understanding and memory, so as to improve the quality of teaching; but we should not pay too much attention to the gorgeous courseware, but should pay more attention to the combination of its scientific nature, teaching nature, and students' interaction [12].

The utilization rate of the virtual central processing unit at time $t$ is

$$
U_{\mathrm{vcpu}}(t)=\frac{t_{u}+t_{s}+t_{i o}+t_{i r q}+t_{s i}}{t_{\text {total }}}=1-\frac{t_{\text {idle }}}{t_{\text {total }}} .
$$

The expression of the prediction model is as follows:

$$
U_{\mathrm{vcpu}}(t)=\cup_{i=1}^{t-1} w_{i}(L)
$$

Among them, $w_{i}$ is the affine transformation obtained by the principle of statistics.

The occupancy rate of the virtual central processing unit is calculated by weighted average, and the expression is as follows:

$$
\bar{U}_{\mathrm{vcpu}}(t)=(1-\gamma) \times \bar{U}_{\mathrm{vcpu}}(t-1)+\gamma \times U_{\mathrm{vcpu}}(t) .
$$

Let $Q_{\mathrm{cpu}}$ be the parallelism of the physical central processing unit; then,

$$
Q_{\mathrm{cpu}}=\frac{l_{\mathrm{vq}}}{n_{\mathrm{vcpu}}}
$$

The probability vector that a user clicks on a certain resource in the future $k$ time intervals is

$$
P(t+k)=P(t) P_{k}=P(t) P_{1}^{(k)} .
$$

The weight of a certain queue is

$$
W_{i}=a_{0} \sum_{j=1}^{k} \mathrm{WT}_{j}+\sum_{l=1}^{m} a_{l} W_{i-l} .
$$

According to experimental statistics, the value of $M$ is 3, and the geometric sequence with a common ratio of 2 has the best effect. Inferred from experimental data,

$$
\begin{aligned}
& W_{0}=a_{0} \sum_{j=1}^{k} \mathrm{WT}_{j}, \\
& W_{1}=a_{0} \sum_{j=1}^{k} \mathrm{WT}_{j}+a_{1} W_{0}, \\
& W_{2}=a_{0} \sum_{j=1}^{k} \mathrm{WT}_{j}+a_{1} W_{1}+a_{2} W_{0} .
\end{aligned}
$$

Let $T_{i}=t_{i}-t_{i-1}$. Then, $T_{i}$ satisfies the probability distribution function:

$$
F_{T_{i} \mid t_{i-1}}\left(t \mid t_{i-1}\right)=1-e^{-\lambda(t) t} .
$$

If $y_{1}, y_{2}, \ldots, y_{n}$ is an independent observation dataset based on a semiparametric partial regular regression model, $X_{1}, X_{2}, \ldots, X_{n}$ is the corresponding common variable, and $u_{1}, u_{2}, \ldots, u_{n}$ is the corresponding nonlinear variable. Then, $\xi=\left(\sigma^{2}, \lambda, \beta^{T}, g^{T}\right)^{T}$ can obtain the log likelihood function as follows:

$$
L(\xi)=\sum_{i=1}^{n}\left(\log 2-\frac{1}{2} \log 2 \pi-\frac{1}{2} \log \sigma^{2}-\frac{\left(y_{i}-X_{i}^{T} \beta-g\left(u_{i}\right)\right)^{2}}{2 \sigma^{2}}+\log \Phi\left(k_{i}\right)\right)
$$

The $P$-spline can be used to estimate the unknown smoothing function $g(\cdot)$. According to the smooth characteristic of $P$-spline, the virtual function $g(\cdot)$ can be expressed as follows:

$$
g(u)=B(u)^{T} \alpha=\alpha_{1} u+\alpha_{2} u^{2}+\cdots+\alpha_{p} u^{p}+\sum_{i=1}^{k} \alpha_{p+i}\left(u-s_{i}\right)_{+}^{p} .
$$

The error covariance equation can be expressed by the following formula:

$$
\widehat{P}_{k}=A_{k-1} P_{k-1} A_{k-1}^{T}+Q .
$$

After the standing phase is detected, the gravity measured by the accelerometer can be used to complete the correction of the system state. The correction process can be written as follows: 


$$
\begin{aligned}
& x_{k}=\widehat{x}_{k}+K_{k}\left(a_{k}-\mathrm{Hg}\right), \\
& P_{k}=\left(I_{7 \times 7}-K_{k} H_{k}\right) \widehat{P}_{k},
\end{aligned}
$$

where $K_{k}$ is the Kalman filter gain, which can be obtained by the following formula:

$$
K_{k}=\widehat{P}_{k} H_{k}^{T}\left(H_{k} \widehat{P}_{k} H^{T}+R\right)^{-1}
$$

The state equation of the moving target in the Cartesian coordinate system is

$$
x(k+1)=F(k) x(k)+\Gamma(k) v(k) .
$$

Here, $x(k) \in R^{n \times 1}$ is the target state vector at time $k$ [13].

2.3. System Design. Network teaching platform is a platform to support sharing and interaction, which provides a certain guarantee for students' learning quality and conforms to the unified standards. It is an essential teaching support platform for modern network teaching. The dynamic process of information dissemination is shown in Figure 1. The dynamic communication process of the six stages of educational communication theory also provides strong theoretical support for network teaching. The network teaching platform also abides by the above six stages in the process of teaching information communication, especially in the evaluation feedback stage. The interactivity and convenience of the network teaching platform are more conducive to the mutual communication between teachers and students and to the timely feedback of evaluation opinions by teachers [14].

The network architecture is the structure and technical foundation of the communication network of the deployment system, and the network architecture must be able to make user access safe. Combining the needs of multimedia network teaching in higher vocational colleges, its users include teachers, academic users, and administrators in the school, as well as student users outside the school. Therefore, the system includes both the school network and the offcampus network. The school users can access the teaching platform resources at high speed. The students outside the school can access the teaching platform remotely through the authentication of identity authority. In order to determine the reliability of the system and the security of data transmission, data backup processing is realized through dual heat engines on the server side $[15,16]$.

\section{Multimedia Teaching System Simulation}

3.1. Experimental Environment. The server operating system configuration is shown in Table 1 . The system adopts a B/S three-tier system structure, based on ASP. NET technology, under the .NET Framework framework, through Visual Studio integrated development tools and C\# language for system design and implementation.

3.2. Testing of the Teaching Platform. The physical education management module is the main module in this sports network teaching platform. Therefore, the physical education management module is tested in the testing process. Each module adopts a black box test method. In the system analysis, by dicing, slicing, rotating, and other operations on the data warehouse constructed with the student's performance data, the student's performance data is observed from different angles, which is convenient for the teacher to understand the teaching effect. Through data mining technology, rules that are instructive to physical education can be obtained [17, 18].

3.3. Construction of Teaching Evaluation System. The multimedia classroom teaching quality evaluation system makes classroom teaching related evaluation indicators specific, diversified, and objective. This article adopts the method of grade evaluation to finally determine a number of indicators that are not contradictory and nonrepetitive. The end of a teaching unit or a series of teaching activities must be evaluated at different levels. The biggest difference between process evaluation and summative evaluation is that it not only attaches importance to objective measurement and quantitative analysis but also attaches importance to the subjective judgment and qualitative analysis of both teaching parties, which requires a combination of the two [19].

3.4. System Test. Because the real-time management data of the remote network teaching platform needs to maintain strict consistency, and the cooperative work system is basically sequential; we adopt the centralized control distributed system structure which is easy to implement and control in the software architecture design of the remote network teaching platform $[20,21]$. When the system is running, it adopts multiserver and object message sharing mechanism, so it can improve the response speed, reduce the delay, reduce the network traffic, and avoid the problems of single server. The test environment of the system is to simulate the real running environment of the system, build a cloud computing service platform in the central computer room of the school, and provide dynamic resource scheduling, dynamic load balancing, and other services [22]. The main function of the client subsystem is to realize the teaching on demand of the resources that users are interested in. Users can obtain the content of resources through the teaching platform recommendation, search, and other ways and use the built-in streaming media player to realize the presentation of streaming media data [23].

3.5. Multimedia Teaching Survey. The collected questionnaires were processed by Excel software, and the tables and charts were drawn according to the data. The test method is chi square test. The reliability of the questionnaire was tested by retest method [24].

\section{System Simulation Results}

4.1. Performance Analysis. We tested and recorded the practicability indicators in the performance indicators and used network simulation software to gradually increase the 


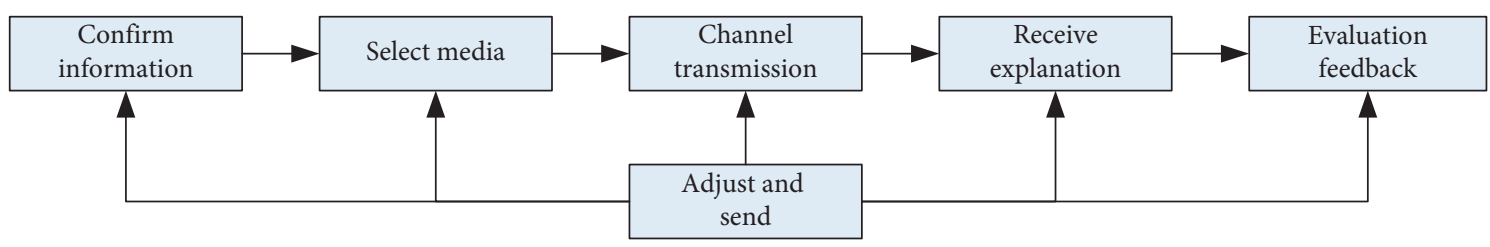

Figure 1: The dynamic process of information dissemination.

TABLE 1: Server operating system configuration.

\begin{tabular}{lccccc}
\hline Server type & Database server & Application server & Flow media services \\
\hline $\begin{array}{l}\text { Software } \\
\text { configuration }\end{array}$ & Solaris 9 & Tomcat & $\begin{array}{c}\text { Windows2000/2003/xp/ } \\
\text { vista }\end{array}$ & Oracle 9i AS & $\begin{array}{c}\text { Windows media format } \\
\text { Windows media } \\
\text { server }\end{array}$ \\
\hline
\end{tabular}

number of concurrent processing users and observe the delay of video on demand resources [25]. The results are shown in Figure 2. When the number of simulated concurrent operations continues to increase, the time delay of teaching video playback is also increasing, but the increase is not linear. Because the system adopts a forecast-based resource scheduling and equalization strategy, the system has a scale of 5000 concurrent users. The playback delay can be less than 2 seconds. When 500 users interact with the server at the same time; that is, when the concurrent user is 500 , the system response time is $1.5 \mathrm{~s}$. When the concurrent user is 2000 , the system response time is about $3 \mathrm{~s}$, which is the interval that the system can accept. The system currently supports the largest 4000 users interact with the server at the same time, and the system response time is about $4 \mathrm{~s}$.

In order to test the resource scheduling algorithm based on prediction, the system designs a comparative test scheme [26]. Under the same test case, the system performance under two states of turning on the dynamic resource scheduling function and turning off the resource scheduling function is tested, respectively. The test results are shown in Table 2. When the number of concurrent operators is increasing, when the dynamic resource scheduling based on prediction is turned on, the average delay of client-side VOD is less because of the reasonable resource scheduling. However, when the function is not turned on, the delay of courseware VOD is obviously increased, which fully proves the effectiveness of the dynamic resource scheduling algorithm.

The comparison of request cancellation rate under different request intensity is shown in Figure 3. In terms of user request cancellation rate, FCFS emphasizes fairness, so it has a higher cancellation rate. Compared with MQL, the cancellation rate of MWQL and MEQL has dropped significantly. According to different user request intensity and different Zipf tilt factors, we can see from the figure that the withdrawal rate is the lowest. In terms of average waiting time, FCFS emphasizes fairness, which makes the waiting time of user requests in the on-demand system the longest. The average waiting time and user request intensity of MEQL are significantly lower than those of MWQL and MQL. It is not suitable for some special subjects, and it is difficult to reflect the individualization of physical education curriculum and teacher teaching, especially the functional system designed for the teaching characteristics of physical education courses has not been well developed. Therefore, combining the characteristics of the teaching of physical education disciplines to carry out research on the functions of the teaching platform system, so that the teaching design and system functions can be coordinated and improved, and the support for teaching and learning under the network environment is more smooth, which is an important research content to be strengthened in this research.

The survey results of students' understanding of information needs are shown in Table 3. Some sports network education resources do not reflect the forefront of the development of sports, nor update and enrich the content in time, which cannot meet the needs of students' learning and exercise. $95 \%$ of the students in the experimental group were very satisfied with the volleyball teaching attitude, while $55 \%$ of the students in the control group were very satisfied with the volleyball teaching attitude. It can be seen that students are more inclined to network multimedia system assisted teaching, which has a positive role in promoting the cultivation of students' interest in learning. The results of the questionnaire also show that all the students in the experimental class can quickly master the use of the network multimedia tennis teaching system, which shows that the students can operate the network multimedia teaching system on the existing network mastering technology, which shows that the system has good operability.

University software facilities are shown in Figure 4. The construction of information infrastructure in colleges and universities in our province has achieved initial results, but the overall level is not high, which is far from the schools in developed areas. Although our province's economy is relatively backward, education funding is tight, but in order to keep up with the pace of the times, all schools have invested a lot of money in the construction of multimedia classrooms and campus network, but not many colleges and universities really do network teaching under modern information technology, especially sports like volleyball teaching; almost no school has its own teaching website. For demonstration ability, $62.6 \%$ of the students think it is very good and $31.6 \%$ of the students think it is good; for the explanation ability of track and field teachers, $60.4 \%$ of the students think it is very good, and $33.1 \%$ of the students think it is good; $54.3 \%$ of the students think it is very strong, and $39.1 \%$ of the students 


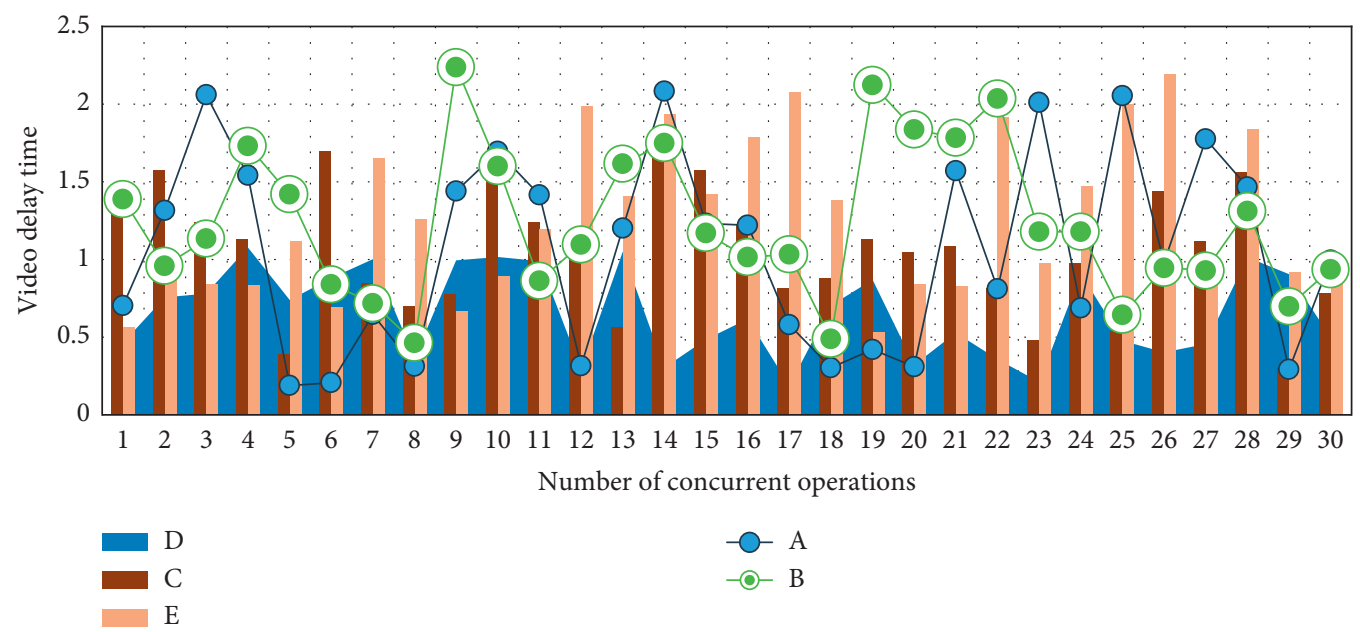

FIGURE 2: System availability index test results.

TABle 2: Performance test results.

\begin{tabular}{lccc}
\hline Number of concurrent operations & Enable dynamic resource scheduling & Turn off dynamic resource scheduling & Difference (seconds) \\
\hline 100 & 0.2 & 0.2 & 0 \\
500 & 0.8 & 1.0 & 0.2 \\
1000 & 1.4 & 3.2 & 1.8 \\
3000 & 1.6 & 4.6 & 3.0 \\
5000 & 1.8 & 5.9 & 4.1 \\
\hline
\end{tabular}

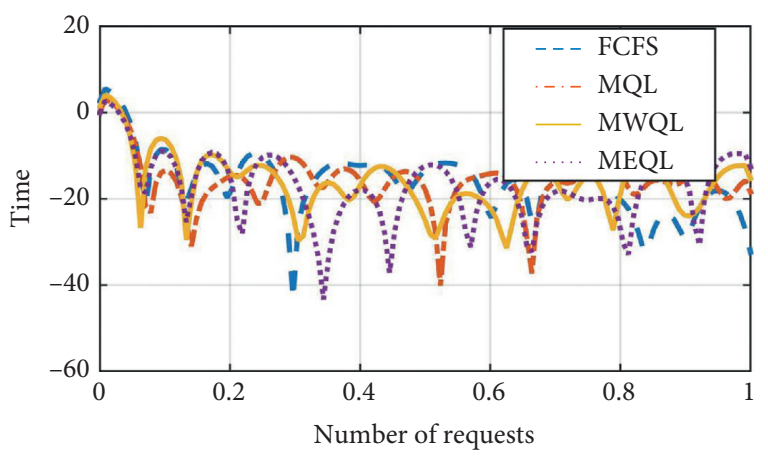

Figure 3: Comparison of request cancellation rates under different request strengths.

think it is strong; $57.6 \%$ of the students think it is very good, and $33.1 \%$ of the students think it is better; in the cultivation of students' innovative thinking ability, $44.7 \%$ of the students think that the track and field teachers do well, and $38.6 \%$ of the students think that the track and field teachers do well.

4.2. Physical Education Teaching Effect. The use of school sports website is shown in Table 4 . From the survey results, the number of no professional sports undergraduate students who have not used sports website is more than that who have used sports website, and the number of professional sports colleges who have used sports website is more than that who have not used sports website. Because the sports website of no professional sports universities belongs to the website of the school sports department, in the selection of courses and query results system, most schools are set up in the campus network, and the sports website of professional sports universities is its campus network, so most students will use the campus network to query results, download forms, select courses, and so on. Among the 260 people surveyed, 102 had used it and 158 had not. Among them, 43 people in no professional sports universities have used it, accounting for $24.57 \%$; 132 people have not used it, accounting for $75.43 \%$. Among 85 people in professional sports colleges, 59 people have used the school sports website, accounting for $69.40 \%$ of the survey, and 26 people have not used it, accounting for $30.60 \%$ of the survey.

Teachers' understanding of modern educational technology is shown in Figure 5. It can be seen from the figure that $10.26 \%$ of teachers know modern educational technology very well, $59.83 \%$ of teachers generally know it, and $29.91 \%$ of teachers do not know it. This shows that teachers have a certain understanding of modern educational technology and begin to pay attention to the application of modern educational technology in teaching. 29\%, 38.14\%, and $52.57 \%$ of the students knew modern educational technology well, and $28.8 \%$ and $64.44 \%$ of the managers knew modern educational technology well. Through the comparison of modern educational technology among teachers, students, and administrators, we find that teachers' understanding of modern educational technology is generally higher than that of students and administrators, and administrators' understanding of modern educational technology is the lowest, which indicates that teachers have begun to apply modern educational technology in teaching, 
TABLE 3: Survey results of students' understanding of information needs.

\begin{tabular}{|c|c|c|c|c|c|c|}
\hline Index & Important & Percentage & General & Percentage & Unimportant & Percentage \\
\hline Access to information & 136 & 100 & - & - & - & - \\
\hline Information technology & 110 & 80.88 & 24 & 17.65 & 2 & 1.47 \\
\hline Lifelong sports & 123 & 90.44 & 11 & 8.09 & 2 & 1.47 \\
\hline Auxiliary teaching & 123 & 90.44 & 12 & 8.82 & 1 & 0.74 \\
\hline
\end{tabular}

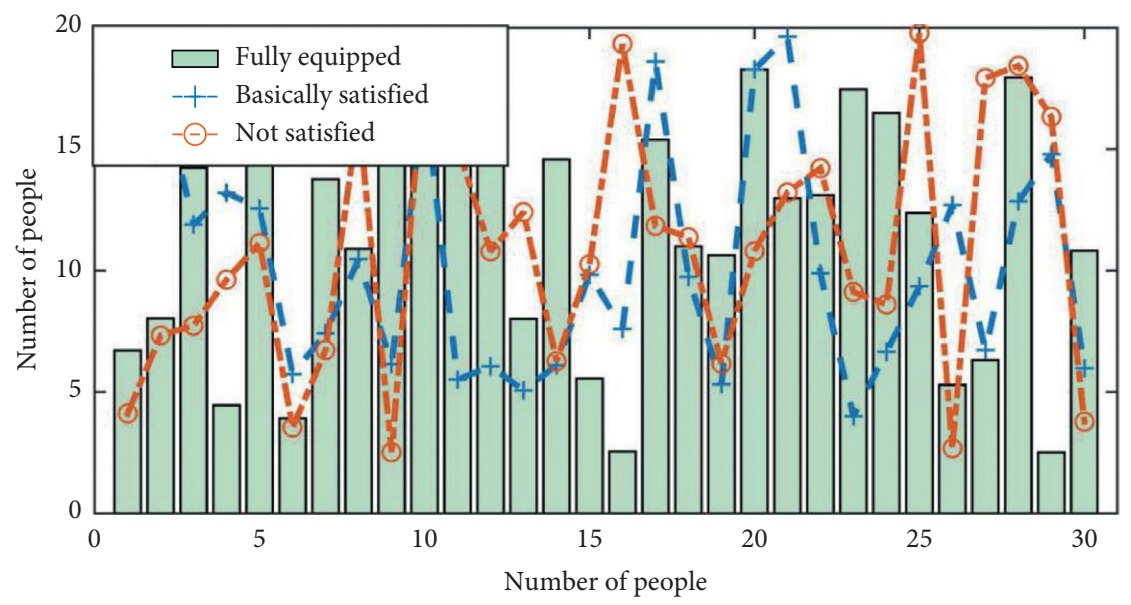

FIGURE 4: Software facilities in universities.

TABLE 4: Usage of school sports website.

\begin{tabular}{lcccc}
\hline & Used & Never used & \\
\hline \multirow{2}{*}{ Nonprofessional sports colleges } & 43 & 132 & 175 \\
\hline \multirow{2}{*}{ Professional sports academy } & $24.57 \%$ & $75.43 \%$ & 100 \\
\hline
\end{tabular}

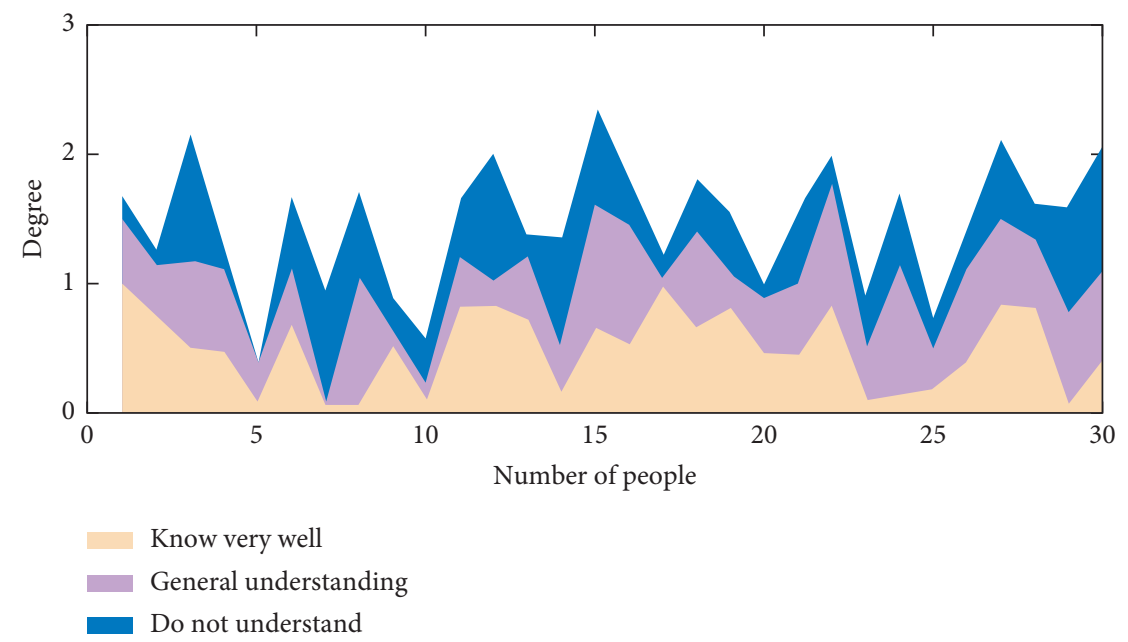

FIGURE 5: Teachers' understanding of modern educational technology.

and gradually begin to understand and master modern educational technology. As the administrators of colleges and universities, managers should strengthen the understanding of modern educational technology, so as to help the application of modern educational technology in colleges and universities.

Figure 6 shows the number of modern teaching equipment used in physical education in colleges and 


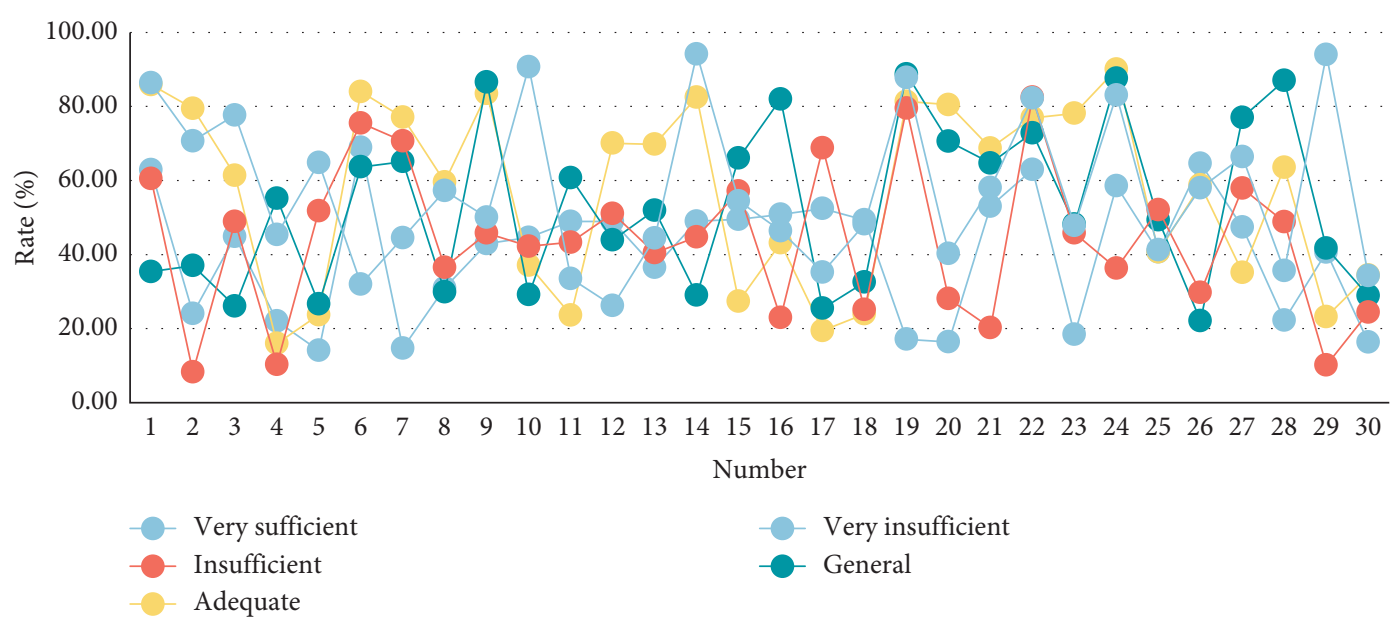

FIGURE 6: The number of modern teaching equipment used in physical education in colleges and universities.

universities. The survey shows that $100 \%$ of colleges and universities in our province already have the basic equipment of modern teaching equipment. Teachers in the province think that teaching equipment is above average accounting for $82.14 \%$, but due to factors such as economic development, region, and teaching development speed, $17.86 \%$ of them think that teaching equipment is insufficient. It can be seen that the modern teaching equipment used for physical education in colleges and universities in our province has been able to meet the basic teaching, but it is still unable to meet the rapid development and high-demand professional fields. For faster-developing schools, it is necessary to introduce or update in time. Teaching equipment is not conducive to the promotion of informationization of physical education.

The effect evaluation of students' audience on sports network course is shown in Figure 7. The students' evaluation of the effect of sports network course is not high, and the average value of the video, animation, and picture of sports network course is 2.77 . It can be seen that although it has certain help for students' learning, the effect of this help has not been fully reflected, and most students still cannot get great help from sports network course. The average value of the convenience degree of sports network course learning is 3.65 , which indicates that some students have obtained more convenient learning content or learning methods from sports network course, but this effect is not prominent. At the same time, combined with the survey results of students' teaching effect and liking degree of sports network course, it can be seen that students prefer sports network course and feel that the teaching effect of sports network course is relatively strong. Among them, $72 \%$ of the students think that the teaching effect of sports network course is better than that of traditional sports course. In addition, $10 \%$ of the students think that the teaching effect of sports network course is very good. At the same time, $74 \%$ of the students prefer sports network courses. From the results of the interview and investigation, we can see that the students and teachers of the normal universities under the ministry have a high sense of identity for the sports network course.

4.3. Multimedia Application Effects. The classification statistics of college sports homepages are shown in Table 5. There are very few schools that use college sports networks to develop educational functions, only reaching $7.8 \%$ of the total number of campus networks. Because of its rich teaching materials and unrestricted learning time, the asynchronous teaching characteristics of physical education network determine that it can take on the learning outside the physical education classroom and become an extension of the physical education classroom to expand the learning content and learning time of students. Physical education cannot be guaranteed to be completed in multimedia classrooms. The number of multimedia classrooms also limits multimedia teaching. The advantages that cannot be reflected in the teaching of physical education. The improvement of teaching quality and the richness of learning resources will affect the factors that teachers choose multimedia teaching.

Table 6 shows the use of modern teaching methods such as multimedia. From the results of the table analysis, 82 people participated in the survey, 79 people answered, and the response rate was $96.3 \%$. Teachers believe that modern educational technology has a great impact on physical education theory classes at $30.77 \%, 55.56 \%$ with an impact, $13.68 \%$ without an impact, $4.27 \%$ with a great impact on physical practice classes, and $26.50 \%$ with an impact, and the unaffected accounted for $69.23 \%$. It can be found that teachers' understanding of current educational technology is limited to theoretical classes. $86.33 \%$ of them believe that 


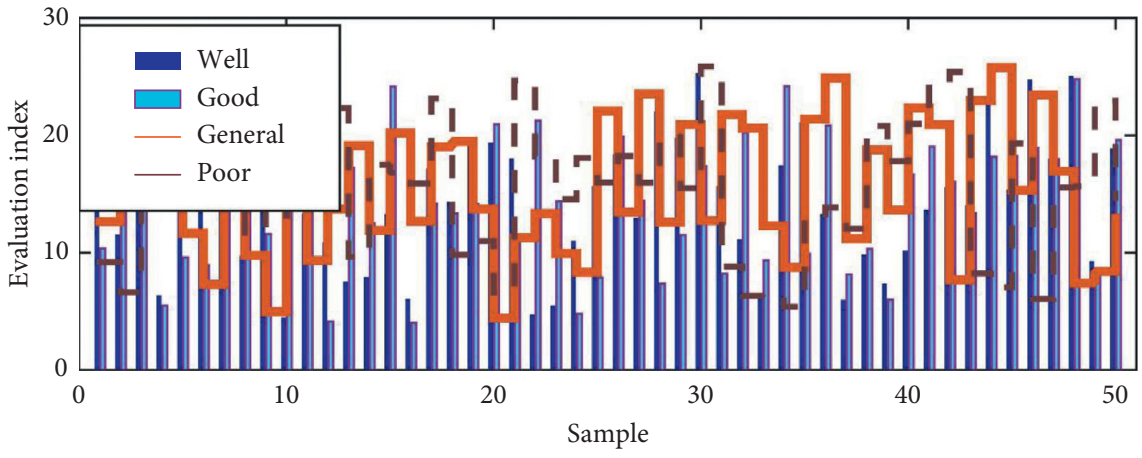

FIgURE 7: The effect evaluation of the student audience on the sports network course.

TABLE 5: Classification statistics of college sports homepages.

\begin{tabular}{lccc}
\hline Site type & Quantity & \% of sports websites & \% of total campus network \\
\hline First category & 34 & 24.8 & 7.8 \\
Second category & 82 & 59.9 & 18.9 \\
Third category & 21 & 15.3 & 4.8 \\
\hline
\end{tabular}

Table 6: The use of modern teaching methods such as multimedia.

\begin{tabular}{cccccc}
\hline & & Frequency & Rate & Effective frequency & Cumulative frequency \\
\hline \multirow{4}{*}{ Effective } & Often & 14 & 17.1 & 17.7 & 17.7 \\
& Occasionally & 56 & 68.3 & 70.9 & 88.6 \\
& Never & 9 & 11.0 & 11.4 & 100.0 \\
\hline
\end{tabular}

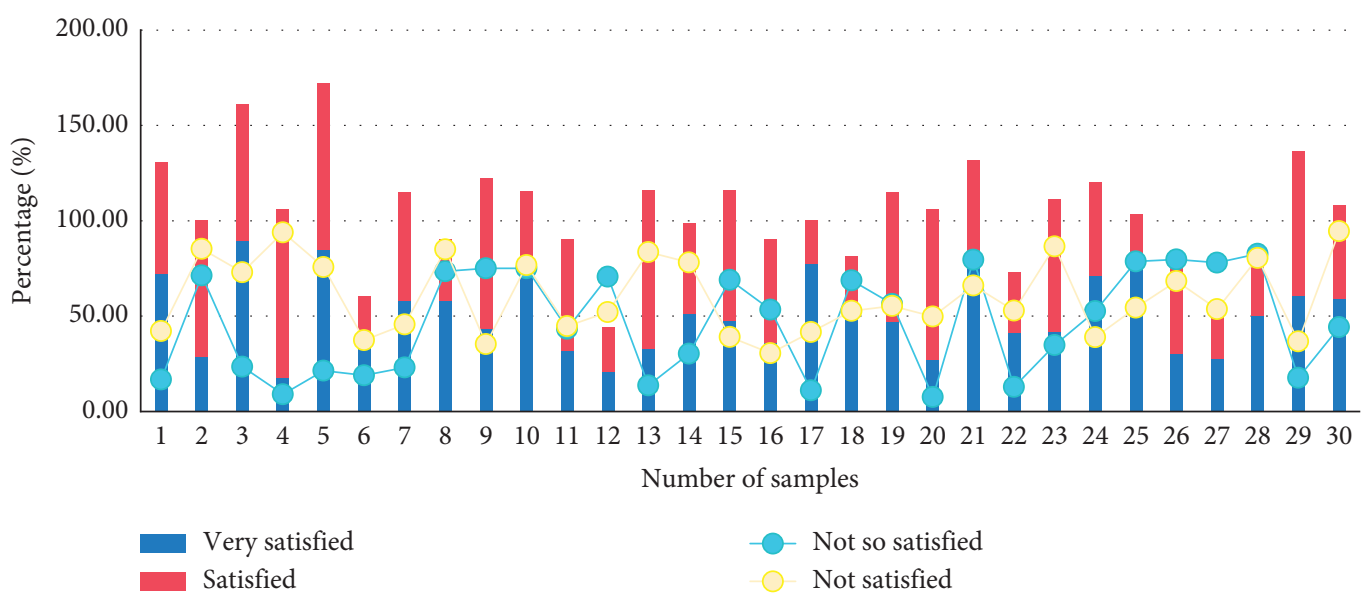

Figure 8: Students' satisfaction with teaching.

modern educational technology has an impact on theoretical classes, and most of them feel that it has no effect on the application of modern educational technology in practical classes.

In the development and construction of college sports network education resources, due to the diversification of its development and construction ways, the country has not formulated a unified standard for the classification and technical indicators of network education resources. In this way, the development process of sports network education resources does not follow a unified development standard, and there is no unified description of the types and data formats of sports network education resources; other systems cannot read resources in a particular database at all. At the same time, there is a lack of association between the application systems, and there are differences in the way of resource storage, so the system is relatively isolated and unsystematic, and the data cannot be automatically 
transferred, which leads to the disorder and repeated development and construction of sports network education resources. With the continuous increase of data, the problems of its standardization and consistency are highlighted, and the interfaces are not compatible with each other, which hinders the sharing rate of college sports network education resources to a great extent. Students' satisfaction with teaching is shown in Figure 8. 93\% of the students surveyed said that they had learned sports theory knowledge through the Internet, of which $8.4 \%$ often learned sports theory knowledge through the Internet, $16.8 \%$ mostly learned sports theory knowledge through the Internet, $48.4 \%$ occasionally learned sports theory knowledge through the Internet, and $26.1 \%$ seldom learned sports theory knowledge through the Internet.

\section{Conclusions}

The construction of multimedia information resources is not only the construction of multimedia software, but also the construction of multimedia hardware resources. These hardware devices include projectors, video recorders, multimedia computers, and cameras. But these devices cannot be configured at will and should be reasonable plan and allocate to various departments to avoid duplicate construction and waste of funds. In the teaching and learning under the information technology environment, the teacher presents and teaches the teaching plan and teaching content to the students through the network and then accepts the students' response, diagnoses, and evaluates, so as to understand the students' learning situation. In this physical education model, the teaching media used is a computer network, which can enhance the teacher's educational role and improve the teaching effect. It fully embodies the teaching thought of taking students as the main body and teachers playing a leading role.

The online teaching platform is used to assist tennis teaching, and the theory is combined with practice, so that students' interest and learning attitude can be truly transformed, so that students' spirit of cooperation and innovation can be effectively improved, and the quality of teaching and the efficiency of learning can be improved. Tennis teaching can be effectively promoted, so that the reform of tennis teaching theory and practice can be continuously strengthened and provide a scientific basis for the reform. The physical education class is mainly carried out through various physical exercises, and most of the teaching time and venue must be completed outdoors. Therefore, although multimedia teaching is an important part of physical education methods, it can only play an auxiliary role due to various conditions in the process of use. Therefore, the research and innovation of this article is based on the system innovation of the college sports network multimedia teaching platform, breaking the restrictions of various conditions.

The development of physical education has been hindered by many factors such as the age of the teacher, the gender of the teacher, and the teacher's personal ability. Standardized demonstration teaching can be carried out through the use of multimedia network teaching platform, so as to ensure the completeness and correctness of the information received by students. At the same time, in order to adapt to the new requirements of the era of establishing comprehensive universities, many colleges and universities have adopted the mode of running schools in different places. All these have brought new problems to network teaching and put forward higher requirements for network teaching. In the face of such a huge amount of data and such rich types of teaching information, in the face of so many users, how to make full use of the scarce storage resources and increase the utilization rate of the network has become the focus of the current network teaching work. Increasing the utilization rate of the network can make teaching standardized teaching, and students' learning information will be more abundant.

\section{Data Availability}

The data used to support the findings of this study are available from the corresponding author upon reasonable request.

\section{Conflicts of Interest}

The authors declare there are no conflicts of interest with respect to the research, authorship, and/or publication of this article.

\section{References}

[1] M. Armenteros, S. S. Liaw, M. J. Sánchez-Franco, M. Fernández, and R. Arteaga Sánchez, "Analysis of FIFA referees and assistant referees' motivational factors towards the Multimedia Teaching Materials," Education and Information Technologies, vol. 22, no. 3, pp. 1-32, 2017.

[2] H. Zheng and Z. Perez, "Design of multimedia engineering teaching system based on internet of things technology," International Journal of Continuing Engineering Education and Life-Long Learning, vol. 29, no. 4, pp. 293-305, 2019.

[3] K. J. Abdurasulovich, K. M. Yangiboevich, A. A. Anvarovich, and G. A. Xolmurodovich, K. O. Abdurasulovich, Opportunities and results to increase the effectiveness of multimedia teaching in higher education," Journal of Critical Reviews, vol. 7, no. 14, pp. 89-93, 2020.

[4] P. Liu, H. Cui, Y. Cao, X. Hou, and L. Zou, "A method of multimedia teaching evaluation based on fuzzy linguistic concept lattice," Multimedia Tools and Applications, vol. 78, no. 21, pp. 30975-31001, 2019.

[5] T.-H. Jiang, S.-L. Chen, and J. K. C. Chen, "Examining the role of behavioral intention on multimedia teaching materials using FSQCA," Journal of Business Research, vol. 69, no. 6, pp. 2252-2258, 2016.

[6] X. Wang, "Discussion on application of multimedia teaching in college English vocabulary teaching," Open Journal of Modern Linguistics, vol. 06, no. 3, pp. 177-181, 2016.

[7] K. Otakhon, "Use of multimedia technologies in teaching foreign language," International Journal on Integrated Education, vol. 3, no. 12, pp. 136-137, 2020.

[8] W. Zhang, "An optimization method for analysing sanda technical movement and teaching by using multimedia 
assisted technology," Boletin Tecnico/Technical Bulletin, vol. 55, no. 8, pp. 188-194, 2017.

[9] Z. Wang, "Study on the multimedia application in college aerobics teaching: a learning interactive perspective," Revista De La Facultad De Ingenieria, vol. 32, no. 2, pp. 759-767, 2017.

[10] Y. Zhao, "Multimedia university teaching design based on audio recognition," IPPTA: Quarterly Journal of Indian Pulp and Paper Technical Association, vol. 30, no. 7, pp. 907-913, 2018.

[11] A. Cao, "Research on the interactive classroom of English situational teaching based on multimedia network," Boletin Tecnico/Technical Bulletin, vol. 55, no. 4, pp. 132-138, 2017.

[12] J. Y. Liu, "Research on independent learning ability based on the network multimedia vocational college English teaching model," Agro Food Industry Hi Tech, vol. 28, no. 1, pp. 3494-3496, 2017.

[13] X. Zhao and Y. Liu, "Research on the design and optimization of English situational teaching assisted by multimedia network platform," Revista de la Facultad de Ingenieria, vol. 32, no. 9, pp. 642-648, 2017.

[14] M. Sun, R. Hao, B. Wang et al., "Analysis on university education reform and teaching based on computer multimedia and network teaching platform," International Journal of Multimedia and Ubiquitous Engineering, vol. 12, no. 1, pp. 377-388, 2017.

[15] M. Dai, "Research on wind music teaching mode innovation and process optimization based on multimedia classroom," Boletin Tecnico/Technical Bulletin, vol. 55, no. 18, pp. 414-419, 2017.

[16] Y. Mu and X. Zha, "Research on the multimedia computer assisted instruction in college wushu teaching and cultural inheritance," Revista de la Facultad de Ingenieria, vol. 32, no. 2, pp. 824-831, 2017.

[17] W. Pingxiao, "Research on the English teaching and autonomous learning based on multimedia platform and smart classroom system," International Journal of Multimedia and Ubiquitous Engineering, vol. 12, no. 1, pp. 351-362, 2017.

[18] F. T. Q. Tursunova, "The role of multimedia teaching tools in English lessons," Theoretical and Applied Science, vol. 84, no. 4, pp. 189-191, 2020.

[19] S. F. D. Patri and S. Heswari, "Development of multimedia teaching materials for problem based learning models using professional 3D pageflip on class X geometry materials," Edumatica | Jurnal Pendidikan Matematika, vol. 9, no. 2, pp. 23-33, 2019.

[20] Z. Min, "Research on the effect appraisement of multimedia teaching in physical education classroom based on information platform," International Journal for Engineering Modelling, vol. 31, no. 1, pp. 15-22, 2018.

[21] C. Yu-Feng, L. Yu-Zhou, F. Xu, and S. Chich-Jen, "Effects of the application of computer multimedia teaching to automobile vocational education on students' learning satisfaction and learning outcome," Eurasia Journal of Mathematics Science and Technology Education, vol. 14, no. 7, pp. 32933300, 2018.

[22] J. Qi, "An optimization approach for flipped classroom and multimedia teaching innovation by contrast with traditional teaching," Boletin Tecnico/Technical Bulletin, vol. 55, no. 8, pp. $480-488,2017$.

[23] C. Wu, "Investigation and statistical analysis on the development of college football based on sports value and multimedia teaching," Boletin Tecnico/Technical Bulletin, vol. 55, no. 18, pp. 260-266, 2017.
[24] Z. Yinxiang, "Multimedia teaching of ideological and political education based on artificial intelligence," Agro Food Industry Hi Tech, vol. 28, no. 1, pp. 683-687, 2017.

[25] S. Wan, L. Qi, X. Xu, C. Tong, and Z. Gu, "Deep learning models for real-time human activity recognition with smartphones," Mobile Networks and Applications, vol. 25, pp. 743-755, 2019.

[26] R. S. Bhadoria and N. S. Chaudhari, "Pragmatic sensory data semantics with service-oriented computing," Journal of Organizational and End User Computing, vol. 31, no. 2, pp. 22-36, 2019. 